\title{
ADA EN LA ENSEÑANZA DE LA PROGRAMACIÓN
}

\section{Luis Marcél Barrero Mendizábal}

\section{RESUMEN}

El objetivo del presente artículo es proponer una metodología para la enseñanza de la programación, basada en los conceptos y principios de la ingeniería del software proponiendo además el lenguaje ADA como el más apropiado para este propósito.

Para respaldar la segunda afirmación, en el artículo de procederá a comparar técnica y objetivamente ADA con otros lenguajes de programación que actualmente son utilizados en la enseñanza.

Palabras Clave: ADA, Ingeniería de Software, Lenguajes de Programación. 